\title{
Using Patient-Reported Outcomes to include the patient in research, care, and quality
}

Priya Gaur ${ }^{1}$, Nikita Jeswani ${ }^{1}$, Nelly Ganesan ${ }^{1}$

${ }^{1}$ Avalere Health - Washington DC

\section{INTRODUCTION}

Despite a lack of consensus on what constitutes an ideal healthcare system, stakeholders have unanimously called for patient-centeredness as a national priority. In the midst of health reform, various health care entities (e.g. providers, hospitals, payers) have sought a deeper understanding of patient-reported outcomes (PROs), which reflect a patient's direct input in assessments of quality of life and value for a particular treatment. In recent years, there have been numerous efforts to integrate well-validated PROs into electronic health records, indicating growth in their importance [1].

Regardless of this interest and growth, several key gaps still remain in the development and routine use of PROs. For example, while PRO measures exist and are used in clinical trials, few are at the point of care in daily clinical practice, and even fewer are translated into quality and performance measures (tying payment to value in public and private programs in the U.S., Europe, and Canada). Furthermore, the PRO measures that do exist lack validation. Significant work needs to be done in order to incorporate greater input to measure self-reported health condition outcomes of greatest interest to the patient and account for gaps. One solution is a rigorous, step-wise, and nimble PRO development and translation approach that accommodates new information and best practices as they emerge [2].

In an effort to better understand the barriers around translation and conceptualize what exactly this nimble and step-wise process could resemble, we developed a translation framework to bridge the gap between integration of PROs into clinical trials and adoption into value-based reimbursement. Based on a survey of publicly-available literature from organizations that have historically had a role in PRO development and implemen- tation, we attempted to define standards for scientific, research, and clinical practicality illustrating ideal or aspirational PRO measure development and implementation [3-12].

\section{PROS FROM RESEARCH TO PRACTICE TO POLICY: A FRAMEWORK}

As a result of this review, we propose four stages that frame the translation of PROs from research to practice to policy (Figure 1). Stage one, issue identification, is to ensure that PROs are targeting meaningful clinical areas and assessing domains of healthcare delivery that other quality metrics cannot, such as health-related quality of life and experience with care. As stakeholders continue to question whether PRO data is meaningful to both the patient and the provider, research and testing emerged as a key second step to make certain that a PRO measure is appropriate and usable to advance scientific knowledge. In the third phase, PRO measures in clinical practice will be able to predicate behavioral changes that drive quality improvement. And, if a PRO measure can successfully be implemented in clinical practice, then it can enter the final phase for implementation into quality and performance measurement. In this stage, measures are utilized to assess value from the patient's perspective in a way that is harmonized with PRO use in other settings.

In designing this framework, one of the overarching aims was to identify and put forth opportunities for patient engagement in the research, care, and quality processes. The growing emphasis on patient centeredness suggests that the use of well-developed PRO measures can safeguard patients' needs and perspectives by assessing how treatment affects them. In research, FDA's Patient-Focused Drug Development (PFDD) provides patients with an opportunity to share input into clinical trial design and investment; the
Corresponding author Priya Gaur

PGaur@avalere.com

\section{Disclosure}

The authors have no conflicts of interest to declare. 


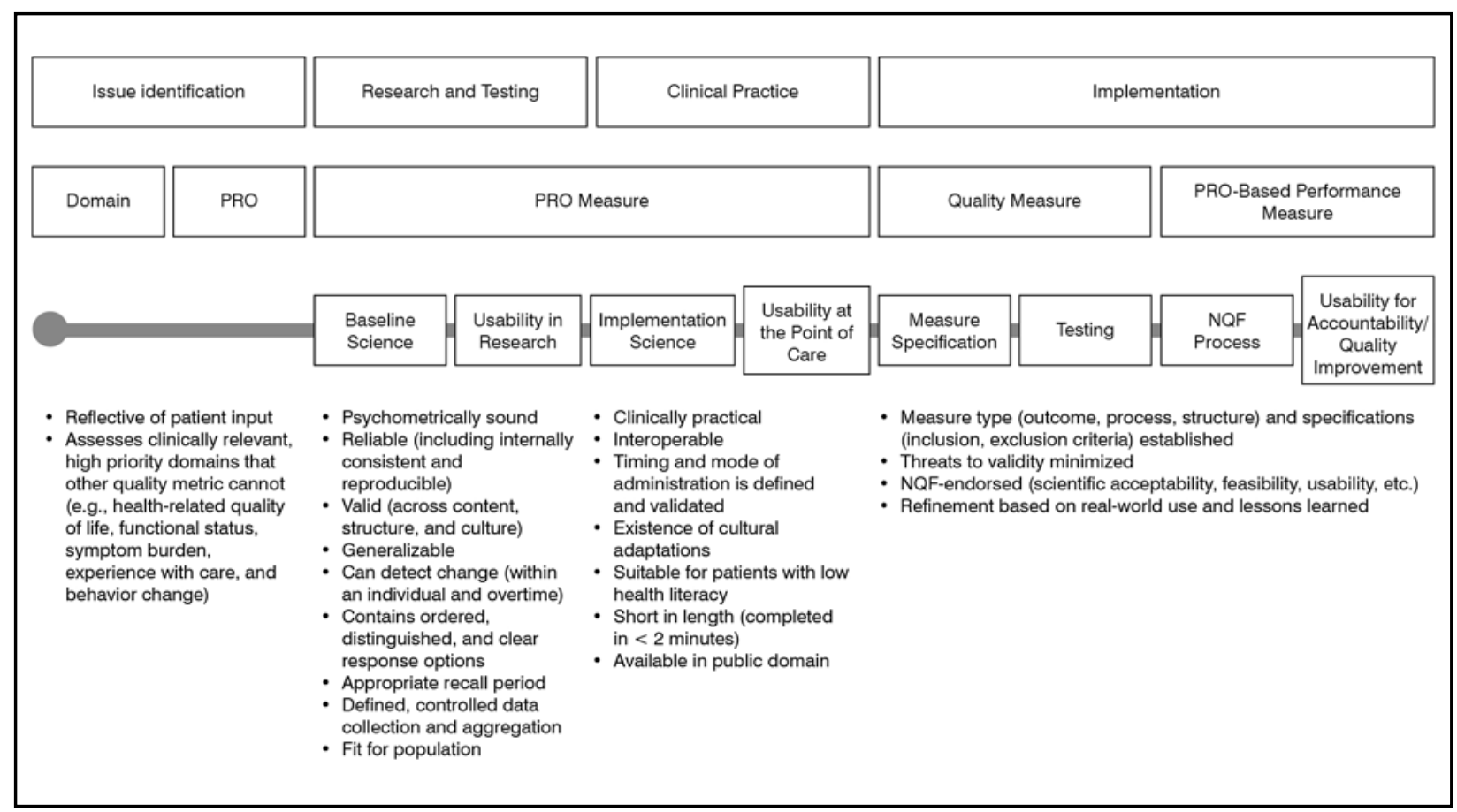

Figure 1. Common Factors and Best Practices Across Four Stages of PRO Translation

use of PROs can help prioritize and capture endpoints that matter most to patients as well as enhance the benefit-risk assessment in regulatory decision making for biopharmaceutical products [15]. PROs can also heighten patient engagement in care processes, as they may provide guidance in determining patient health goals. Finally, robust PROs can support efforts to define value in the healthcare system more broadly and capture what is truly important to the patient.

Avalere is neither the first, nor the last, stakeholder to dedicate time and thought to the issue of PRO translation from clinical trial to value-based reimbursement and the associated challenges. For example, the National Quality Forum (NQF) and the Patient-Centered Outcomes Research institute (PCORI) are focusing their efforts on the technical concerns related to the translation of PRO measures for use as performance measures [16-18]. Additionally, England's National Health Service has examined PRO measure data collection methods and associated opportunities to optimize patient response rates. In the context of this developing field, the stages identified in our framework put forward a process that begins to address some of the broader technical and methodological concerns with PRO translation. Increased attention on PRO translation is expected in the future; European countries have already made substantial progress towards the shift, and Health and Human Services (HHS) recently announced a goal of tying payment to value through alternative payment models and participation in reporting programs. The framework provides guidance on translating PROs from use to actual measurement that can be linked to payment.

\section{CONCLUSIONS}

In the face of increased attention and activity around PRO translation, how can we ensure that patients are genuinely consulted and engaged throughout the PRO translation process? One possible place is determining whether patients are fully engaged throughout each of the four steps in our framework. For example, under the research and testing step, there is an opportunity for patients to play a role, thereby helping to determine if the PRO measure is fit for purpose. Still, though the framework provides a potential path forward in the PRO translation environment, considerable work still remains before such a framework can be implemented and adopted widely. Before we can move forward with entering measures through the framework, we must ensure that they are truly designed with the patient perspective in mind, and to that end, measure what matters most to patients: "Can I dance with my granddaughter at her wedding?" or "Will I be able to walk up the stairs?" Increasingly we are seeing interest in developing PRO measures with somewhat less quantifiable patient-reported outcomes (e.g., compassion, hope). With this careful attention to measure development comes a realization that, in some instances, the measures that matter to patients may not 
align with those that are of high priority for providers.

We must reconcile this tension as we continue to shift towards a patient-centered healthcare system. Stakeholders looking at the big picture must continue to be thoughtful and deliberate in including patients in developing pa- tient-centered efforts. While such efforts - our framework, included - are developed with the intent of placing patients at the center, there exists an opportunity to learn from best practices on how to execute on that vision and position ensure patients as partners throughout the development of patient-centered activities.

\section{REFERENCES}

1. Institute of Medicine. Crossing the Quality Chasm: A New Health System for the $21^{\text {st }}$ Century. March 2001

2. Avalere Health. A Multi-Stakeholder Vision for Patient-Centered Measurement in New Payment and Delivery Models. Available at: http://avalere.com/expertise/life-sciences/insights/avalere-white-paper-facilitating-a-transitionto-using-pros-to-measure-perf

3. Terwee CB, Mokkink LB, Knol DL, et al. Rating the methodological quality in systematic reviews of studies on measurement properties: a scoring system for the COSMIN checklist. Qual Life Res 2012; 21: 651-7; http://dx.doi. org/10.1007/s11136-011-9960-1

4. Roseman D, Osborne-Stafnes J, Amy CH et al. Early Lessons from Four 'Aligning Forces for Quality' Communities Bolster the Case for Patient-Centered Care. Health Aff (Millwood) 2013; 32: 232-41; http://dx.doi.org/10.1377/ hlthaff.2012.1085

5. Perfetto E, Burke L, Oehrlein E, et al. Systematic, methodologically sound actions taken to partner with patients in health care decision making, health research and development, and similar activities. Medical Care 2015; 53: 9-17

6. Parsons S, Winterbottom A, Cross $\mathrm{P}$, et al. The quality of patient engagement and involvement in primary care. An inquiry into the quality of general practice in England. The King's Fund 2010

7. National Institutes for Health. PROMIS Instrument Maturity Model. Approved 11, 2012

8. National Institutes for Health. PROMIS - Dynamic Tools to Measure Health Outcomes from the Patient Perspective. Available at: http://www.nihpromis.org/?AspxAutoDetectCookieSupport=1\#1

9. Eton DT, Beebe TJ, Hagen PT, et al. Harmonizing and consolidating the measurement of patient-reported information at health care institutions: a position statement of the Mayo Clinic.. Patient Relat Outcome Meas 2014; 5: 7-15; http://dx.doi.org/10.2147/PROM.S55069

10. Deutsch A, Smith L, Gage B, et al. Patient-reported outcomes in performance measurement: commissioned paper on PRO-based performance measures for healthcare accountable entities. Available at: http://www.qualityforum. org/Projects/n-r/Patient-Reported_Outcomes/Patient-Reported_Outcomes.aspx\#t=2\&s=\&p=2|

11. Coulter A. Patient Engagement - What Works? J Ambul Care Manage 2012; 35: 80-9; http://dx.doi.org/10.1097/ JAC.0b013e318249e0fd

12. Conway PH, Mostashari F, Clancy C. The Future of Quality Measurement for Improvement and Accountability. JAMA 2013; 309: 2215-6; http://dx.doi.org/10.1001/jama.2013.4929

13. Hall LK. HIT Policy and Standards Committee. Patient Generated Data Hearing. June 20, 2012.

14. Center for Patient and Family-Centered Care. HIMSS Patient Engagement Framework. 10 February 2014. Available at: http://www.himss.org/ResourceLibrary/genResourceDetailPDF.aspx?ItemNumber=28305

15. A Call to Action Health for Reform. AARP. Available at: http://assets.aarp.org/rgcenter/health/beyond_50_hcr.pdf

16. U.S. Food and Drug Administration. Guidance for Industry, Patient-Reported Outcome Measures: Use in Medical Product Development to Support Labeling Claims. Fed Regist 2009; 74: 65132-133. Available at: http://www.fda. gov/downloads/Drugs/Guidances/UCM193282.pdf

17. National Quality Forum. Patient Reported Outcomes (PROs) in Performance Measurement. January 2013. Available at: https://www.qualityforum.org/Publications/2012/12/Patient-Reported_Outcomes_in_Performance_Measurement. aspx

18. NQF. Prioritizing Gaps: Patient-Centered Care and Outcomes. Available at: http://www.qualityforum.org/projects/ prioritizing_measures/person_centered_care/ $\# \mathrm{t}=1 \& \mathrm{~s}=\& \mathrm{p}=$

19. Patient-Centered Outcomes Research Institute. Patient-Reported Outcomes (PRO) Infrastructure Workshop. November, 2013. http://www.pcori.org/events/patient-reported-outcomes-pro-infrastructure-workshop/ 